\title{
An Idea Whose Time Has Come? An African Foresight Observatory on Genomics Medicine and Data-Intensive Global Science
}

\author{
Collet Dandara ${ }^{1, *, \#}$, Clement Adebamowo ${ }^{2,3, *}$, Jantina de Vries ${ }^{1}$, Edward S. Dove ${ }^{4}$, Erik Fisher ${ }^{5}$, \\ Richard A. Gibbs ${ }^{6}$, Peter J. Hotez ${ }^{7,8, *}$, Ilona Kickbusch ${ }^{9}$, Bartha M. Knoppers ${ }^{4,10, *}$, Mario Masellis ${ }^{11}$, \\ Mikkel Z. Oestergaard ${ }^{12, *}$, Tikki Pang ${ }^{12,13, *}$ and Charles N. Rotimi ${ }^{14, *}$
}

\begin{abstract}
${ }^{I}$ Division of Human Genetics, Faculty of Health Sciences, University of Cape Town, Anzio Road, Observatory 7925, South Africa; ${ }^{2}$ West African Bioethics Training Program and the Institute of Human Virology, Abuja, Nigeria; ${ }^{3}$ Department of Epidemiology and Public Health, School of Medicine, University of Maryland, MD, USA; ${ }^{4}$ Centre of Genomics and Policy, Department of Human Genetics, Faculty of Medicine, McGill University, Montreal, QC, Canada; ${ }^{5}$ School of Politics and Global Studies, Consortium for Science, Policy \& Outcomes, Center for Nanotechnology in Society, Arizona State University, Tempe, AZ, USA; ${ }^{6}$ Department of Molecular and Human Genetics and Human Genome Sequencing Center, Baylor College of Medicine, Houston, TX, USA; ${ }^{7}$ National School of Tropical Medicine at Baylor College of Medicine, Houston, TX, USA; ${ }^{8}$ Sabin Vaccine Institute and Texas Children's Hospital Center for Vaccine Development, Baylor College of Medicine, Houston, TX, USA; ${ }^{9}$ Global Health Programme, Graduate Institute of International and Development Studies, Geneva, Switzerland; ${ }^{10}$ Public Population Project in Genomics (P3G), Montreal, QC, Canada; ${ }^{11}$ L.C. Campbell Cognitive Neurology Research Unit, Sunnybrook Research Institute, Department of Medicine (Neurology), Sunnybrook Health Sciences Centre, Toronto, Canada; ${ }^{12}$ Initiative on Genomics and Public Health, World Health Organization, Geneva, Switzerland; ${ }^{13}$ Department of Research Policy and Cooperation, World Health Organization, Geneva, Switzerland; ${ }^{14}$ Center for Research on Genomics and Global Health, National Human Genome Research Institute, Bethesda, MD, USA
\end{abstract}

Keywords: Africa, genomics and biobanks 101, global health diplomacy and public health pharmacogenomics, global personalized medicine, neglected tropical diseases, socio-technical integration research (STIR), vaccinomics and personalized vaccines, West African Bioethics Training Program.

"Africa is the Center of the World."

Fela Anikulapo Kuti (Musician and Pioneer of Afrobeat, Nigeria; 1938-1997) [1]

"Today most discoveries are made by scientist-clinicians who are funded to generate data, build a model or hypothesis, provide a validation of their idea, and then share the results as a paper in a peer-reviewed journal. But as the scale of the data needed to make insights grows (...) the power of coordinated team approaches will grow. By analogy to physics, astronomy, and the writing of the software, the benefits of dynamic teams sharing data and ideas in real time will multiply. The logical extension is to start considering a "commons" where omics data, projects, and models can be evolved in a shared manner."

Stephen Friend [2]

\footnotetext{
Address correspondence to C. Dandara at University of Cape Town, South Africa, E-mail: collet.dandara@uct.ac.za; C. Adebamowo at the West African Bioethics Training Program, Ibadan, Nigeria, Institute of Human Virology, Abuja, Nigeria and Institute of Human Virology, University of Maryland, Baltimore, MD 21201, USA; E-mail: cadebamo@yahoo.com; P.J. Hotez at the National School of Tropical Medicine at Baylor College of Medicine, Houston, TX, USA, E-mail: hotez@bcm.edu; B.M. Knoppers at Centre of Genomics and Policy, McGill University, Montreal, QC, Canada, E-mail: bartha.knoppers@mcgill.ca; M.Z. Oestergaard at Initiative on Genomics and Public Health, World Health Organization, Geneva, Switzerland, E-mail: oestergaardm@who.int; T. Pang at Department of Research Policy and Cooperation, World Health Organization, Geneva, Switzerland, E-mail: pangt@who.int and C.N. Rotimi at the Center for Research on Genomics and Global Health, National Human Genome Research Institute, Bethesda, MD, USA, E-mail: rotimic@mail.nih.gov

"Authorship is listed alphabetically after the first author.
}

\section{MOVING TOWARD GLOBAL SCIENCE}

An analysis of the Web of Science database has found that the contribution of Africa to the world's global scientific output has shown little change over the past 30 years (1980 to 2009), remaining at a mere $1 \%$ [3]. It would be a mistake, however, to think that this predicament cannot be remedied. In recent years, new political commitments to integrate diplomacy and international development agendas [4], public and private investments, and capacity building are rapidly changing the scientific landscape and expectations for knowledge-based innovations in the continent [5-7].

The African Society of Human Genetics (AfSHG) was established in 2003 to bridge the widening gap between 
Africa and the Western world in biomedical science, with the inaugural conference held on December 8-9, 2003 in Accra, Ghana [8]. The AfSHG aims to build capacity for the African scientific community and policy-makers in the field of genetics research and develop avenues for collaboration across the continent as well as internationally.

Nigerian musician and social visionary Fela Anikulapo Kuti has aptly noted that Africa is the center of the world, embodying the recognition that the origins of humanity reside in the continent. For genomics medicine to be valid and useful for world populations, research and development must focus on the strong genetic diversity in Africa and the African environmental context [9, 10]. Investments in genomics research in Africa not only help address the extant equity gaps in global science, but are also essential for good science [10]. The Ethics and Genomics Research in Africa (EAGER-AFRICA) Conference, which concluded recently in Abuja, Nigeria on Nov 28-29, 2011, underscored this dual significance of capacity-building for genomics research in Africa [10].

Indeed, Africa is now arguably becoming the 'epicenter' of genomics research investments: the Human Heredity and Health in Africa (H3Africa) Initiative is building momentum to accelerate the study of genomics and environmental determinants of common diseases with the goal of improving the health of African populations [11]. H3Africa is a consortium of African scientists, enabled by international partners such as the Wellcome Trust in the UK and the National Institutes of Health (NIH) in the US, that aims to bridge the research, expertise, and infrastructural genomics gap that Africa currently faces $[5,11]$.

Researchers engaged in social studies of science and technology have long emphasized that the social and economic benefits of biotechnologies such as genomics, especially in Low and Middle-Income Countries (LMICs), are not automatic (i.e., "they do not flow inevitably from the marriage of biology and technology") [12-16]. Frequent contacts and integration between knowledge generators (e.g., scientists, technology designers) and end-users (e.g., citizens, individual patients, policy-makers and the public health community), as well as the creation of mechanisms between supply and demand of knowledge, are necessary for biotechnology innovations that are attuned to societal norms, contextually sensitive and thus, socially robust and sustainable [12, 17, 18]. Lavis et al. [19] recommend that:

Researchers (and research funders) should create more opportunities for interactions with the potential users of their research. They should consider such activities as part of the 'real' world of research, not a superfluous add-on.

Observatories and knowledge synthesis platforms are being established under this ethos in many countries and global regions. For example, the UK Government Foresight Horizon Scanning Centre was created in 2005 for strategic future(s) thinking to promote robust decision-making and public policy that is resilient to future uncertainties and cognizant of the wider societal values that crucially shape technology and innovation futures [20]. In these early days of genomics applications in Africa, together with the enthusiasm for genomics-driven healthcare and global personalized medicine brought about by the launch of H3Africa, planning ahead for the possibility of an "African Foresight Observatory on Genomics Medicine and DataIntensive Global Science" would be timely [21].

An African Foresight Observatory could help analyze and anticipate the potential outcomes of genomics applications for population health in Africa while keeping vigilance on new antipoverty drugs, vaccines, diagnostics, and emerging fields such as vaccinomics that are directly pertinent for public health in LMICs [22-24]. Yet another charge for this Observatory could be to contribute to the development of rigorous scientific merit review in Africa. Indeed, Subra Suresh, Director of the US National Science Foundation (NSF), has observed that the "most fundamental barrier to bilateral and multi-lateral international collaborations are disparate standards for scientific merit review and differences in the infrastructures that ensure professional ethics and scientific integrity" [25]. Much of the extant barriers to large-scale international genomics research are related to the lack of international consensus on appropriate governance structures, particularly for $21^{\text {st }}$ century infrastructure science such as biobanks [26-30]. Moreover, Fisher has recently noted [31]:

Science policy mandates across the industrialized world insinuate more active roles for publics, their earlier participation in policy decisions, and expanded notions of science and technology governance. In response (...) scholars in science studies have sought to design and conduct exercises aimed at better attuning science to its public contexts.

In this spirit, this editorial analysis brings together an international set of scholars in genomics sciences, global health, personalized medicine and social studies of science and technology. We present descriptions of emerging (and anticipated) applications of genomics that benefit public health and personalized medicine in South Africa and Nigeria, as well as new genomics/omics technology applications in public health (vaccinomics and personalized vaccines) for neglected tropical diseases (NTDs).

\section{LESSONS FROM SOUTH AFRICA}

South Africa is a melting pot for most races in the world and is aptly named the "rainbow nation" [5]. Allele and genotype distributions in South Africa often differ from other African and world populations. There is a high level of genetic diversity, low linkage disequilibrium, and presence of rare variants, which make the use of currently available commercial genotyping kits/platforms questionable in the region [32].

South African genetics researchers have started efforts to work together and decode the genomes of the different ethnic and racial groups in the country. This initiative has been spearheaded by the Southern African Society for Human Genetics (SASHG) that launched the Southern African Human Genome Program (SAHGP) in 2011, whose main aim is to sequence a sizeable number of Southern African individuals emanating from different ethnic and racial groups in order to help unravel the genetic variability among South Africans and Africans in general. 
In addition to the efforts by SASHG, 2011 saw the advancement of genetics in Africa through calls for funding under the H3Africa theme. As of early 2012, peer-reviewed and selected projects are being funded, which will contribute to some of the goals of SAHGP. However, it is important to note that South African researchers have already embraced the concept of working in collaborative interdisciplinary teams, with access to large patient cohorts in order to accelerate genomic discoveries. To this end, a one-day "Pharmacogenomics Symposium" was hosted by the Division of Human Genetics at the University of Cape Town in December 2011, bringing together six research institutions in South Africa and researchers from Zimbabwe and Malawi, all with an interest in pharmacogenomics. Although funding is always a major constraint, the meeting resolved to make optimal use of the available resources in order to start harmonization in the collection of samples, phenotyping, and administration of informed consent. Centralized sample characterization, data sharing and training of young researchers were extensively debated, demonstrating that Africans are taking genomics research seriously.

At the same time, a "Pharmacogenomics Research Consortium" has been conceived, with the initial proposal to concentrate on HIV/AIDS pharmacogenomics to capture the virus diversity across the continent and overlay it with the human genetic diversity, thereby teasing out combinations of viral/human sequences associated with reduced or increased susceptibility, as well as treatment response profiles. The Consortium initially comprises research groups from 10 African countries: Botswana, Cameroon, Ethiopia, Malawi, Nigeria, South Africa, Tanzania, Uganda, Zambia and Zimbabwe. This geographic diversity means that for any particular disease model, the genetic heterogeneity of the African people, as well as disease phenotype variability, can be captured, ultimately leading to the discovery of host genetic factors associated with particular disease outcomes. In most of these Consortium countries, there is very little or no prior pharmacogenomics-related research (see the article featuring Malawi in the current issue of CPPM). However, this initiative, together with the 1000 Genomes Project, is going to contribute towards more African genomes being sequenced. Success in decoding African genomes will greatly contribute to rational drug administration, not to mention potential benefits to be accrued from rational use of essential medicines with companion essential diagnostics that may be developed in the near future [6].

\section{LESSONS FROM NIGERIA}

Despite the central role of Africa in human history, its diverse geography and peoples, and the contribution of African genomes to several recent diasporas, there remains a paucity of genomic research in Africa [33]. This has led some to describe a "genomics gap" that is akin to the other gaps - economic, political and social that separate the people of Africa from the rest of the world. Thus far, the high potential for Africa's contribution to understanding human genetics, health, disease and environmental interactions has not delivered. The good news is that this is changing rapidly in some areas whereas not quite fast enough in others.
The last few decades has seen an increasing number of genomics research in communicable and non-communicable diseases being conducted in Africa. These have encompassed areas as fundamental as the International HapMap Project; disease specific areas such as human cancers, HIV, malaria, sleeping sickness; population history and migration studies; and pharmacogenomics [33-35]. However, a characteristic of many of these projects is the paucity of African leadership, limited implementation of accompanying basic science laboratory work in African laboratories, limited control of the focus and priorities of the research by African scientists and institutions, limited impact on African indigenous capacity, lack of local funding, and concerns about ethical oversight.

Recent developments presage better times for genomics research in Africa. Many African scientists are being motivated by the AfSHG to form local/country societies of human genetics (e.g., Egypt, Ethiopia, Nigeria, Cameroon and Ghana). There is now an imminent infusion of resources and capacity into African genomics research through an international peer review process by the NIH and the Wellcome Trust - H3Africa. There is development of local capacity to engage in genomics ethics review and research led by the NIH-funded West African Bioethics Training Program in Ibadan, Nigeria, culminating, for example, in the Ethics of Genomics Research in Africa program. There is increasing availability of genomics resources and significant reduction in costs, as well as increasing general and scientific interest and awareness of the value of genomics research and its potential impact on African public health [35]. These foundations that have been carefully laid hold the potential for real advancements and gains in genomics research in Africa.

\section{COMMUNICABLE AND NON-COMMUNICABLE DISEASES IN AFRICA}

\subsection{Vaccinomics and the Case of Neglected Tropical Diseases in Africa}

The NTDs comprise a group of 17 high prevalence and chronic parasitic and related infections that are the most common infections of the world's poorest people -especially among the "bottom billion" -- which refers to the 1.4 billion people who live below the World Bank poverty level [36]. A 2009 study published in the Public Library of Science revealed that Africa accounts for all of the world's cases of sleeping sickness and Loa loa infection, more than $90 \%$ of the world's cases of schistosomiasis, onchocerciasis (river blindness), and yellow fever, approximately one-half of the world's lymphatic filariasis (elephantiasis), trachoma, and Buruli ulcer, and one-quarter to one-third of intestinal helminth infections [37].

Indeed, most of sub-Saharan Africa's 400 million people who live on practically no money (i.e., below the World Bank poverty figure) are infected with one or more NTD, each potentially a disease that actually traps people in poverty because of the effects of such conditions on child development, pregnancy outcome and worker productivity [37]. A particularly troubling recent discovery is that millions of girls and women with female genital schistosomiasis 
(FGS) face a three to four-fold risk of acquiring HIV/AIDS [38]. Today, FGS represents one of the most important cofactors in Africa's AIDS epidemic. Despite the overwhelming public health and economic importance of NTDs, subSaharan Africa has been largely on "the outside looking in" with respect to the development of new NTD drugs, diagnostics, and vaccines. To our knowledge, the continent's only NTD vaccine producer is the Institut Pasteur Dakar (Senegal), which produces a World Health Organizationcertified yellow fever vaccine [39].

One of the important recent breakthroughs in vaccine development has been the proof-of-concept for reverse vaccinology first pioneered by Rino Rappuoli and his colleagues, which facilitates the selection, expression, and testing of specific antigens based on genomic and bioinformatic data and algorithms [40]. Genome projects have provided the sequence of reference strains for many NTD pathogens, and could greatly stimulate the molecular studies that underpin reverse vaccinology and production of effective vaccines. With the recent rise of vaccinomics, the convergence of data intensive omics science and classical vaccinology, rational vaccine design and targeted vaccine administration for more safe and effective use in global public health are becoming a reality [23].

With focused genomic approaches and the future development of an African Foresight Observatory on Genomics Medicine, a shift can occur from restrospective studies of disease history to real-time analysis of pathogen ecology. The combination of health care management practice in Africa, the intrinsic diversity of African populations, and the prevalence of pathogens driving the NTDs, can become an opportunity to improve many aspects of global health care.

\subsection{Neurodegenerative Diseases in Africa}

\subsubsection{Potential Application of Platform-Based Approaches to Personalized Medicine}

Dementia and other neurodegenerative diseases are increasing in prevalence worldwide, with Alzheimer's and Parkinson's being the most common. This increase in prevalence is also seen in developing nations and is largely driven by an increase in the number of older adults living with medical co-morbidities, which can accelerate the underlying neurodegenerative process. A Delphi consensus study by the 10/66 Dementia Research Group identified that although about $60 \%$ of people with dementia lived in developed nations in 2001, which is significantly higher than that seen in developing nations, the predicted rate of proportionate increase in dementia prevalence from 2001 to 2040 in developed nations is expected to be $100 \%$ whereas for Africa and the Middle East it is expected to range between $235 \%$ to $385 \%$ [41]. Therefore, the future socioeconomic burden of dementia and neurodegenerative diseases in Africa will be enormous. One reason for this is that as the AIDS epidemic matures, those with poorly managed HIV infection will "age faster" and have an increased susceptibility to common co-morbid diseases such as cardiovascular risk factors, among others [42, 43]. There is emerging evidence to suggest that treatments targeted at the underlying neurodegenerative process will not be successful once the disease has been diagnosed and there has been a paradigm shift to identifying the earliest stages of disease using neuroimaging, genomic and proteomic biomarkers [44]. It is hoped that these approaches will eventually allow for the identification of pre-symptomatic neurodegenerative states such that future disease-modifying strategies can be employed at the earliest stages for prevention [44].

Several landmark international studies in developed nations are now underway using platform-based "omics" approaches to study sporadic Alzheimer's disease (Alzheimer's Disease Neuroimaging Initiative [ADNI]) [45] and Parkinson's disease (Parkinson's Progression Markers Initiative [PPMI]) [46], as well as familial forms of Alzheimer's (Dominantly Inherited Alzheimer Network [DIAN]) [47] and frontotemporal dementia (The GENetic Frontotemporal Dementia Initiative [GENFI]). It is hoped that similar platform-based "omics" approaches in Africa may also be conducted in the near future to reduce the effects of the anticipated neurodegenerative epidemic.

\section{WORLD HEALTH ORGANIZATION INITIATIVE ON GENOMICS AND PUBLIC HEALTH}

Genomics has a long history at the World Health Organization (WHO), and is informing several objectives and programmatic activities at the WHO both for chronic and infectious diseases. For example, in 2002, the WHO's Advisory Committee on Health Research (ACHR) identified genomics as an important area with implication for world health [48], and in 2010, the WHO Human Genetics Programme published a report on Community Genetics Services in developing countries [49]. Most recently, in 2010, the WHO Department of Research Policy and Cooperation established the WHO Initiative on Genomics and Public Health (IGPH) as a WHO-wide initiative wide initiative that serves as a focal point for genomics at the WHO and aims to place genomics within the wider context of WHO's mission, priorities and core functions [50]. IGPH works primarily to strengthen capacity for research and application of genomics in clinical and public health, and to promote research on genomics and public health in developing countries. IGPH is currently undertaking the WHO Grand Challenges in Genomics for Public Health in Developing Countries project - a large consultation and priority-setting exercise of several hundred international experts in genomics and public health to identify the top 10 key priorities for the effective development and application of genomics-based interventions for public health improvement in developing countries. Conceivably, the proposed African Foresight Observatory [21] would have considerable synergies with such existing initiatives in global public health genomics.

\section{BIOBANKS 101 INITIATIVE FOR GENOMICS CAPACITY-BUILDING IN AFRICA}

Global genomics demands innovation not only in science and technology, but also in public policy and governance frameworks so as to appropriately recognize and target the nuances of a data-intensive, dynamic and global postgenomics $21^{\text {st }}$ century science [51-53]. For example, Pullman et al. note [54]: 
Despite (...) enthusiastic predictions about the research benefits to be achieved through the exploitation of biobanked specimens and related information, there is continuing concern that this potential may not be realized soon. The problem is the lack of international consensus on appropriate regulatory standards and governance structures for biobanks."

The Public Population Project in Genomics and Society $\left(\mathrm{P}^{3} \mathrm{G}\right)$ is a non-profit international consortium focused on optimal access and use of population biobanks and databases [55]. $\mathrm{P}^{3} \mathrm{G}$ aims to lead, catalyze and coordinate international efforts and expertise to optimize the use of genomics studies, biobanks, research databases and other similar health and social research infrastructures for the improvement of individual and population health. $\mathrm{P}^{3} \mathrm{G}$ will be integrating its current repository of information and tools into one 'user-oriented' web interactive kit: "Biobanks 101". This open access web platform will offer users a step-by-step approach for the development and maintenance of a population biobank. Biobanks 101, conceivably, could be embedded or integrated with the African Foresight Observatory to help researchers in resource-limited settings to build a biobank in their own region, including in rural communities, regardless of the extant vast geographical distances among research centers in the continent. Looking further, Biobanks 101 and similar initiatives that sustain and advance population biobanks can be linked to a summer school or a web tutorial offered at a global level so as to reach out 'live' to countries who are developing infrastructure science but have limited expertise in biobanks, including the ethical and legal issues.

\section{GENOMICS ACROSS BORDERS}

\section{1. 'Different Places, Same Ethics' or 'Different Places, Different Ethics'?}

Historically, research collaborations involving African research participants have been of limited benefit to the people inhabiting the continent. Although advances in the treatment of certain conditions have improved the outlook for patients suffering from those conditions, many drugs remain unaffordable or unavailable to most. Furthermore, research funding often remains geared towards particular conditions - mostly, HIV/AIDS, TB and malaria - while many other important diseases remain uninvestigated. Today, genomics research on the African continent will need to be oriented towards the broad spectrum of diseases affecting the African population, and will need to have a clearly articulated path for translation of findings into clinical practice.

At least part of the problem may be that the majority of research in Africa is being done by researchers who are not based on the continent, mostly because of severe infrastructural challenges in Africa. Because of this, practices such as large-scale sample export remain common. More attention needs to be paid to the development of technological infrastructure that promotes fair and equal research collaboration between research partners across the globe [56].
Targeting only some (members of) population groups will not necessarily yield benefit for all Africans, partly because of high genetic diversity in Africa but also because some groups may already be disadvantaged or privileged in healthcare systems. A genomic focus on some groups may make available to this group healthcare innovations that remain unavailable to others. Ethical and legal issues such as genetic discrimination will need to be considered when expanding genomics research to the African continent.

Lastly, healthcare provision in many African settings remains constrained. The investment of very large sums of money into science will only be justifiable if there is a clear and direct path for the translation of findings into clinical practice. The 'bench to bedside' trajectory needs not only the support of scientists and universities, but also by other public health institutions and programs in the country. Taken together, research ethics in Africa needs to move beyond 'one-size-fits-all' as exemplified further by the discussion below and lessons learned in Nigeria and West Africa.

\section{NEED FOR CO-EVOLUTION OF LAW AND GENOMICS SCIENCE IN AFRICA}

As genomics research continues its torrid pace of discovery, clinical translation, and (overdue) transnational outreach to underserved regions such as Africa, it is worthwhile to reflect on the need for an accompanying science and law ecosystem in the continent. In any field, the rules and regulations (explicit and implicit) that constitute law, whether local, national, or international, exist as an allencompassing system (nomos) to govern the field's contours and shape its relationship with society. In genomics, relevant laws may address privacy and data protection, biobanking, human subjects protection, discrimination, national health infrastructure, biosafety, and international health regulations (such as those promulgated by the WHO). The aspirational shift from local to global - or "glocal" [57] - genomics will entail a necessary recognition that integrated innovation and research is a direct result of increasingly dynamic interfaces between global health and multiple sectors [58], all of which are affected by science and law systems.

Unfortunately, these systems habitually talk past each other. Law is often self-siloed, hermetically sealed from cross-discipline education and engagement, and cloaks itself in rhetoric of "final" authority. While some might perhaps view co-evolved law and science as an idealistic endeavour, repeating the banal belief that "scientific and technological innovation inevitably outpaces the corresponding and necessary legal and regulatory response" [59], this is by no means "inevitable" in an era increasingly marked by collaborative governance. A law-science divide impedes the formulation of well-drafted, collaboratively/networkengaged genomics-related legislation that is sufficiently open to anticipate possible future events [60], yet coherent enough to minimize unintended consequences. Moreover, perpetuating the divide will cause law to fail in its broader mission to not only protect, but promote, health, whose determinants are not shaped by a Westphalian system. If law - especially transnational law - is to play a strategic role in supporting genomics medicine and data-intensive global science, particularly in the region most severely and unjustly 
affected by poor health, it must be brought into the fold as a vital part of the African Foresight Observatory. Yet, rather than grafting itself onto the structure as a silo, law must take root $a b$ initio and be co-produced as part of a larger, collaborative, co-evolving social structure [61] that includes data-intensive science, technology, and genomics medicine. Doing so will facilitate genomics-relevant legislation and policies in Africa and beyond that are consistent in their aims and implementation yet suitably diverse in their character.

\section{SOCIO-TECHNICAL INTEGRATION RESEARCH (STIR)}

\subsection{Concept of Integrated-Responsible Innovation and Relevance for Foresight Observatory}

Policy-makers are slowly beginning to recognize that the hoped-for benefits from new and emerging science and technology depend on complex relationships among social, cultural and economic factors. Accordingly, investments in basic science are increasingly accompanied by mandates for interactions among scientists, users and various other groups. As calls for "responsible innovation" resonate across Europe and North America, new tools are being developed to open up and strengthen diverse connections between science and society.

In order to help design and assess efforts aimed at responsible innovation, the STIR program in "SocioTechnical Integration Research" has embedded social scientists into over 25 scientific laboratories in a dozen nations on three continents. As we report elsewhere, "social researchers learn the theory and observe the methods of their laboratory counterparts, but they also introduce a protocol that unpacks social and ethical dimensions of the lab science itself in a real-time, hands-on, collaborative manner" $[62,63]$.

Results demonstrate that intensive, collaborative activities such as these can enable laboratory work to become more sensitive to its broader social contexts without compromising laboratory research, education or strategic goals $[64,65]$. The benefits from these collaborative activities also flow in multiple directions, with social researchers able to take what they learn in the laboratory with them out into clinical and policy contexts as well [66].

While each lab setting and national culture is unique, the STIR program has found that critical reflection in science can have similar results across a diverse and globally distributed range of labs. Conceivably, the anticipated integrative activities in the African Foresight Observatory could play a number of roles, including building shared capacity across diverse social, cultural and epistemological communities in Africa.

\section{GLOBAL HEALTH DIPLOMACY}

\subsection{Moving Forward Both Health and Peace Agendas with the African Foresight Observatory}

Genomics across borders and the ethical considerations involved, diverse country experiences and various global personalized medicine initiatives - issues that have been touched upon so far in this paper - have emphasized the growing complexity of the 21 st century. It has brought attention to the interlinkages between compound issues such as health, sustainable development, financial stability, (human) security and peace as part of an overcrowded global agenda, which requires new ways of interaction between policy makers and scientists across disciplines and national borders. In this rapidly changing context, what has been framed "global health diplomacy" invites discussion on the diverse opportunities to tackle, beyond concrete symptoms, the broader structural challenges for health and peace.

As viruses can cross continents within hours, without respect for any borders, and disease can threaten peace, development and economic growth, more interest has been attracted to the system and the method of the multilevel and multi-actor negotiation processes that shape and manage the global policy environment for health, referred to as global health diplomacy.

Three "dynamics" are worth mentioning in this respect. The first is linked to the shifts in geopolitics where more countries want to play an active role, and where regional dialogue becomes much more important. African states are no exception and are increasingly realizing the mutual benefit of speaking with one stronger voice. This has been the case for example most recently at the 130th Session of the WHO Executive Board (EB) in January 2012, where individual countries have spoken on behalf of the African continent, supporting each others positions during the deliberations and the drafting of resolutions. Second, there is a growing recognition that the promotion of robust decision making "resilient to future uncertainties and cognizant of the wider societal values that crucially shape technology and innovation futures" (building on Section 1 of this editorial analysis) can benefit from "collaborative interdisciplinary teams" bringing together different perspectives for health. The third point is linked to the need to respond to raising accountability standards, through a legitimate decision making process. And as one of the members on the WHO EB said, sound research and science have a key role.

A shared effort that brings together scientific expertise from a multi-faceted continent could however have much broader consequences: it can contribute to strengthening the habit of communication, a thickening of relations, and even alliance building that go beyond health and contribute to peace and stability [67].

\section{A FINAL NOTE: CHARTING THE COURSE FOR THE AFRICAN FORESIGHT OBSERVATORY}

Global health is in dire need of extensive, real-time and in-depth analysis of differential population responses to drugs and vaccines, a field where personal genomics is poised to make an important contribution. In relation to the well-recognized global health challenge of noncommunicable diseases, for example, the potential of personalized cancer therapy based on personal genomics science has been highlighted [68]. At a more systemic level, research into the ways in which routine generation of personal genomics information will affect health systems should be a high 
priority for research $[69,70]$. In times of financial crisis and competing priorities, improved efficiency of health care delivery via genomics medicine and more effective and rational use of interventions are clearly important objectives, especially for LMICs.

Public health genomics and personalized medicine, if applied effectively and equitably, can go a long way to achieving the WHO's mission of "the attainment by all peoples of the highest possible level of health". The achievement of this noble aim must, however, be accompanied by initiatives preferably owned by the very target group which can derive the most benefit. In this regard, the "African Foresight Observatory on Genomics Medicine and Data-Intensive Global Science" could help to evaluate the benefits of genomics applications for personalized medicine in Africa, as well as monitoring emerging areas of research and development of novel interventions such as drugs, vaccines, and diagnostics. Lessons derived from the African experience could also be of great value to LMICs in other parts of the world, thus contributing to global health improvement more broadly. Finally, the proposal for an African Foresight Observatory [21] symbolizes a new relationship among $21^{\text {st }}$ century science, publics, governments and research funders where "science is understood as being embedded in social and political life, rather than separated from it" [71].

\section{ABBREVIATIONS}

$\begin{array}{ll}\text { ADNI } & =\text { Alzheimer's Disease Neuroimaging Initiative } \\ \text { ASFHG } & \text { African Society for Human Genetics } \\ \text { DIAN } & =\text { Dominantly Inherited Alzheimer Network } \\ \text { GENFIT } & =\text { GENetic Frontotemporal Dementia Initiative } \\ \text { HIV/AIDS } & =\text { Human Immunodeficiency Virus/Acquired } \\ \text { LMICs } & =\text { Lowmunodeficiency Syndrome } \\ \text { NIH } & =\text { National Institutes of Health } \\ \text { NSF } & =\text { United States National Science Foundation } \\ \text { NTDs } & =\text { Neglected Tropical Diseases } \\ \text { PPMI } & =\text { Parkinson's Progression Marker Initiative } \\ \text { SAHGP } & =\text { Southern African Human Genome Program } \\ \text { SASHG } & =\text { Southern African Society for Human } \\ \text { STIR } & =\text { Genetics } \\ \text { WHO } & =\text { Wocio-technical Integration Research } \\ \text { WHO EB } & =\text { World Health Organization Executive Board }\end{array}$

\section{CONFLICT OF INTERESTS}

None declared/applicable.

\section{ACKNOWLEDGEMENTS}

The analysis, concepts and work reported herein were supported by the following grants to the authors: $C$.
Dandara: National Research Foundation (NRF), Medical Research Council (MRC) of South Africa; E. Fisher (the US National Science Foundation grant number 0849101); B.M. Knoppers (Canada Research Chair in Law and Medicine and Genome Québec/Canada); C. Adebamowo (US National Institutes of Health grants FIC/NIH 2R25TW007091-07; FIC/NIH S07 TW008840-01; FIC/NIH 3R25 TW00709107S1). Supported in part by the Center for Research on Genomics and Global Health (C.N. Rotimi) through grants from the National Human Genome Research Institute, the National Institute of Diabetes and Digestive and Kidney Diseases, the Center for Information Technology, and the Office of the Director at the National Institutes of Health (1ZIAHG200362-02). All authors made a significant contribution to this editorial analysis and interpretation of data; drafting the article or revising it critically for important intellectual content; and approved the final version to be published. The views expressed in this article are the personal opinions of the authors and do not necessarily represent the positions of their affiliated institutions or the funding agencies. The idea of an African Foresight Observatory on Genomics Medicine and Data-Intensive Global Science was first proposed at the EAGER-Africa Conference (November 28-29, 2011) in Abuja, Nigeria [21]. This editorial article was peer-reviewed.

\section{REFERENCES}

[1] Kuti FA, Ayers R. Music of Many Colors, Audio Track A. 1980.

[2] Friend S. Thinking outside the genome. The Scientist 2011 (October). Available from: http://the-scientist.com/2011/10/01/ opinion-thinking-outside-the-genome/ [Accessed February 7, 2012].

[3] Science Metrix. 30 years in science. Secular movements in knowledge creation. Science Metrix 2010. Available from: http:// www.science-metrix.com/30years-Paper.pdf [Accessed February 7, 2012].

[4] Hotez PJ. Unleashing "civilian power": a new American diplomacy through neglected tropical disease control, elimination, research, and development. PLoS Negl Trop Dis 2011; 5(6): e1134.

[5] Warnich L, Drögemöller BI, Pepper MS, et al. Pharmacogenomic research in South Africa: Lessons learned and future opportunities in the rainbow nation. Curr Pharmacogenomics Person Med 2011; 9(3): 191-207.

[6] Kamal SM, Warnich L, Ferguson LR, et al. Forward Look: Tenth anniversary of the human genome sequence and 21st century postgenomics global health - A close up on Africa and women's health Curr Pharmacogenomics Person Med 2011; 9(3): 148-155.

[7] Irikefe V, Vaidyanathan G, Nordling L, et al. Science in Africa: The view from the front line. Nature 2011; 474(7353): 556-9.

[8] Rotimi CN. Inauguration of the African Society of Human Genetics. Nat Genet 2004; 36(6): 544.

[9] Rotimi CN, Jorde LB. Ancestry and disease in the age of genomic medicine. N Engl J Med 2010; 363: 1551-8.

[10] Rotimi CN. Conceptual Framework of the Human Heredity and Health in Africa. Ethics and Genomics Research in Africa (EAGER-AFRICA) Conference, Abuja, Nigeria, Nov 28-29, 2011. Available from: http://eager-africa.com/ea/slide.php [Accessed February 7, 2012].

[11] Abdelhak S, Adebamowo C, Adeyemo A, et al. Harnessing genomic technologies toward improving health in Africa: opportunities and challenges. Available from: http://h3africa.org/ h3africa_whitepaper.pdf [Accessed February 7, 2012].

[12] Ommer R, Wynne B, Downey R, et al. Pathways to Integration. Vancouver: Genome British Columbia GSEAC Subcommittee on Pathways to Integration, 2011. Available from: www.genomebc.ca/ index.php/download_file/view/611/910/ [Accessed on February 7, 2012]. 
[13] Lehoux P. Moving beyond our mutual ignorance. Or, how would engaging the public benefit the personalized medicine community? Curr Pharmacogenomics Person Med 2011; 9(2): 76-9.

[14] Wynne B. Lab work goes social, and vice versa: Strategising public engagement processes: commentary on: "What Happens in the Lab Does Not Stay in the Lab: Applying Midstream Modulation to Enhance Critical Reflection in the Laboratory". Sci Eng Ethics 2011 Oct 21 [Epub ahead of print].

[15] Ozdemir V, Muljono DH, Pang T, et al. Asia-Pacific Health 2020 and genomics without borders: co-production of knowledge by science and society partnership for global personalized medicine. Curr Pharmacogenomics Person Med 2011; 9(1): 1-5.

[16] Ozdemir V, Knoppers BM. From government to anticipatory governance. Responding to challenges set by emerging technologies and innovation. In: Governance for Health in the 21st Century. Kickbusch I. (Editor). New York: Springer 2012 (in press).

[17] Landry R, Amara N, Pablos-Mendes A, et al. The knowledge-value chain: A conceptual framework for knowledge translation in health. Bull World Health Organ 2006; 84(8): 597-602.

[18] Daudelin G, Lehoux P, Abelson J, et al. The integration of citizens into a science/policy network in genetics: governance arrangements and asymmetry in expertise. Health Expect 2011; 14(3): 261-71.

[19] Lavis JN, Ross SE, Hurley JE, et al. Examining the role of health services research in public policymaking. Milbank Q 2002; 80: 125-54.

[20] The Foresight Horizon Scanning Centre for Strategic Futures Thinking, Government of United Kingdom. Available from: http://www.bis.gov.uk/foresight/our-work/horizon-scanning-centre [Accessed February 7, 2012].

[21] Ozdemir V. The moral, philosophical and legal foundations of the ethics of genomics research: towards anticipatory ethics. Ethics and Genomics Research in Africa (EAGER-AFRICA) Conference, Abuja, Nigeria, Nov 28-29, 2011. Available from: http://eagerafrica.com/ea/slide.php [Accessed February 7, 2012]

[22] Hotez PJ. New antipoverty drugs, vaccines, and diagnostics: a research agenda for the US President's Global Health Initiative (GHI). PLoS Neg1 Trop Dis 2011; 5: e1133.

[23] Ozdemir V, Pang T, Knoppers BM, et al. Vaccines of the 21st century and vaccinomics: data-enabled science meets global health to spark collective action for vaccine innovation. OMICS 2011; 15(9): 523-7.

[24] Khoury MJ. Muin J. Khoury discusses the future of public health genomics and why it matters for personalized medicine and global health. Curr Pharmacogenomics Person Med 2009; 7(3): 158-63.

[25] Suresh S. Moving toward global science. Science. 2011; 333(6044): 802.

[26] Ozdemir V, Rosenblatt DS, Warnich L, et al. Towards an ecology of collective innovation: Human Variome Project (HVP), Rare Disease Consortium for Autosomal Loci (RaDiCAL) and DataEnabled Life Sciences Alliance (DELSA). Curr Pharmacogenomics Person Med 2011; 9(4): 243-51.

[27] Knoppers BM, Hudson TJ. The art and science of biobanking. Hum Genet 2011; 130(3): 329-32.

[28] Kaye J. From single biobanks to international networks: developing e-governance. Hum Genet 2011; 130(3): 377-82.

[29] Kickbusch I. Governance for health in the 21st century. Geneva: WHO Regional Office for Europe 2011. Available from: http:// www.euro.who.int/__data/assets/pdf_file/0010/148951/RC61_InfD oc6.pdf. [Accessed February 7, 2012].

[30] Ozdemir V, Smith C, Bongiovanni K, et al. Policy and dataintensive scientific discovery in the beginning of the 21 st century. OMICS 2011; 15(4): 221-5

[31] Fisher E. Editorial overview : public science and technology scholars: engaging whom? Sci Eng Ethics 2011; 17(4): 607-20.

[32] Dandara C, Lombard Z, Du Plooy I, et al. Genetic variants in CYP $(-1 A 2,-2 C 9,-2 C 19,-3 A 4$ and $-3 A 5), V K O R C 1$ and $A B C B 1$ genes in a black South African population: a window into diversity. Pharmacogenomics 2011; 12: 1663-70.

[33] Campbell MC, Tishkoff SA. African genetic diversity: implications for human demographic history, modern human origins, and complex disease mapping. Annu Rev Genomics Hum Genet 2008; 9: 403-33.

[34] International HapMap Consortium. Integrating ethics and science in the International HapMap Project. Nat Rev Genet 2004; 5: 467-75.
[35] Adebamowo CA. West African Bioethics Training Program: Raison D'etre. Afr J Med Med Sci 2007; (Suppl 36): 35-8.

[36] Hotez PJ, Aksoy S. An interfaith dialogue on the neglected tropical diseases. PLoS Negl Trop Dis 2011; 5(12): e1240.

[37] Hotez PJ, Kamath A. Neglected tropical diseases in sub-saharan Africa: review of their prevalence, distribution, and disease burden. PLoS Negl Trop Dis 2009; 3(8): e412.

[38] Mbabazi PS, Andan O, Fitzgerald DW, et al. Examining the relationship between urogenital schistosomiasis and HIV infection. PLoS Negl Trop Dis 2011; 5(12): e1396.

[39] Australian Government, Department of Health and Aging. Yellow fever fact sheets. 2010. Available from: http://www.health.gov.au/ internet/main/publishing.nsf/Content/ohp-yellow-fever-certificatefactsheet.htm [Accessed February 7, 2012].

[40] Sette A, Rappuoli R. Reverse vaccinology: developing vaccines in the era of genomics. Immunity 2010; 33(4): 530-41.

[41] Ferri CP, Prince M, Brayne C, et al. Global prevalence of dementia: a Delphi consensus study. Lancet 2005; 366 (9503): 2112-7.

[42] Justice AC. Commentary: Treated HIV infection is a chronic disease: the case against cause of death analyses. Int $\mathbf{J}$ Epidemiol 2010; 39 (1): 146-8.

[43] Mills EJ, Rammohan A, Awofeso N. Ageing faster with AIDS in Africa. Lancet 2011; 377 (9772): 1131-3.

[44] Lang AE. Clinical trials of disease-modifying therapies for neurodegenerative diseases: the challenges and the future. Nat Med 2010; 16 (11): 1223-6.

[45] Alzheimer's Disease Neuroimaging Initiative. Available from: http://www.adni-info.org [Accessed February 6, 2012].

[46] Parkinson's Progressive Marker Initiative. Available from: http://www.ppmi-info.org [Accessed February 6, 2012]

[47] Dominantly Inherited Alzheimer Network. Available from: http://dian-info.org [Accessed February 6, 2012].

[48] World Heath Organization, Advisory Committee on Health Research. Genomics and World Health. Geneva: WHO, 2002. Available from: http://whqlibdoc.who.int/hq/2002/a74580.pdf. [Accessed February 7, 2012].

[49] World Heath Organization, Human Genetics Programme, Publications. Geneva: WHO, 2010. Available from: http://www. who.int/genomics/publications/en/. [Accessed February 7, 2012].

[50] World Heath Organization, The Initiative on Genomics \& Public Health. Geneva: WHO, 2010. Available from: http://www.who.int/ rpc/igph/en/index.html. [Accessed February 7, 2012].

[51] Knoppers BM. Genomics and policymaking: from static models to complex systems? Hum Genet 2009 May; 125(4): 375-9.

[52] Ozdemir V. Pharmacogenomics: Reflections on the old and new social, ethical and policy issues in postgenomics medicine. In: Pharmacogenomics in Psychiatry. Schwab M, Kaschka W, Spina E. (Eds.), Basel: S. Karger AB (2010), pp. 12-29.

[53] O'Neill O. Broadening bioethics: clinical ethics, public health and global health. Nuffield Council on Bioethics Annual Lecture 2011. Available from: http://www.nuffieldbioethics.org/news/ [Accessed February 7, 2012]

[54] Pullman D, Etchegary H, Gallagher K, et al. Personal privacy, public benefit, and biobanks: A conjoint analysis of policy priorities and public perceptions. 2011; Genet Med 2011; Sep 26 [Epub ahead of print].

[55] Public Population Project in Genomics (P3G) 2011. Available from: http://www.p3g.org [Accessed on February 7, 2012].

[56] De Vries J, Bull S, Doumbo OK, et al. Ethical issues in human genomics research in developing countries. BMC Med Ethics 2011; 12: 5

[57] Kickbush I. Global + local $=$ glocal public health. J Epidemiol Community Health 1999; 53(8): 451-2.

[58] Hill PS. Understanding global health governance as a complex adaptive system. Glob Public Health 2011; 6(6): 593-605.

[59] Conley JM, Doerr AK, Vorhaus DB. Enabling responsible public genomics. Health Matrix Clevel 2010; 20(2): 325-85.

[60] Dove ES. The genetic privacy carousel: A discourse on proposed genetic privacy bills and the co-evolution of law and science. Curr Pharmacogenomics Person Med 2011; 9(4): 252-63.

[61] Bunge M. Social science under debate: A philosophical perspective. Toronto: University of Toronto Press 1998.

[62] Fisher, Biggs S, Lindsay S, et al. Research thrives on integration of natural and social sciences. Nature 2010; 463: 1018 
[63] Consortium for Science, Policy \& Outcomes, College of Liberal Arts and Sciences, Arizona State University. STIR Video. Available from: http://www.cspo.org/scisip/movies/\#movies [Accessed February 7, 2012].

[64] Schuurbiers D. What happens in the lab: Applying midstream modulation to enhance critical reflection in the laboratory. Sci Eng Ethics 2011; 17(4): 769-88.

[65] Fisher E. Ethnographic invention: Probing the capacity of laboratory decisions. NanoEthics 2007; 1(2): 155-65.

[66] Conley SN. Engagement agents in the making: On the front lines of socio-technical integration. Commentary on 'Constructing productive engagement: Pre-engagement tools for emerging technologies'. Sci Eng Ethics 2011; 17(4): 715-21.

[67] Kickbusch I, Buss P. Global health diplomacy and peace. Infect Dis Clin North Am 2011; 25(3): 601-10.
[68] Hayden EC. Personalized cancer therapy gets closer. Nature 2009; 458: $131-2$

[69] McGuire AL, Cho MK, McGuire SE, et al. Medicine. The future of personal genomics. Science 2007; 317(5845): 1687.

[70] Prainsack B, Wolinsky H. Direct-to-consumer genome testing: opportunities for pharmacogenomics research? Pharmacogenomics 2010; 11(5): 651-5.

[71] Guston DH. The demise of the social contract for science. Misconduct in science and the nonmodern world. In: Program in Science, Technology, and Society. Massachusetts Institute of Technology. Working paper number 19, 1992. Available from: http://web.mit.edu/STS/pubs/pdfs/MIT_STS_WorkingPaper_19_G uston_2.pdf [Accessed February 7, 2012]. 